\title{
O USO DE FERRAMENTAS DE GESTÃO NAS PROPRIEDADES FAMILIARES DE PINHEIRO PRETO - SC
}

\author{
Nadir Paula da Rosa ${ }^{1 *}$, Sonia Maria Hentz ${ }^{2}$. Adão Mauri Pauzini Junior ${ }^{3,}$ Gilson \\ Ribeiro Nachtigall ${ }^{4}$ \\ * Autor para correspondência
}

1.Universidade Federal do Rio Grande do Sul (UFRGS), doutoranda em Desenvolvimento Rural (PGDR) e Professora no Instituto Federal Catarinense Campus Vieira/ SC, Brasil (nadir@ifc-videira.edu.br).

2. Especialista em Agronegócios e Desenvolvimento Rural pelo Instituto

Federal Catarinense- Campus Videira / SC.

3. Especialista em Agronegócios e Desenvolvimento Rural pelo Instituto

Federal Catarinense- Campus Videira / SC.

4. Professor no Instituto Federal Catarinense- Campus Videira / SC

Recebido em: 08/04/2017 - Aprovado em: 10/06/2017 - Publicado em: 20/06/2017 DOI: 10.18677/EnciBio 2017A78

\begin{abstract}
RESUMO
A agricultura familiar é uma forma de produção, responsável pela geração de renda de muitas famílias brasileiras. A propriedade rural, mesmo que familiar, precisa ser encarada como uma empresa, onde os agricultores devem ser considerados empresários que visam lucros, controlam custos, planejam e gerenciam suas atividades. O objetivo desta pesquisa foi identificar como ocorre a gestão, quais as principais ferramentas de gestão utilizadas pelos produtores e quais principais fatores influenciam na adoção dessas ferramentas, nas propriedades familiares de Pinheiro Preto - SC. Para alcançar este objetivo, utilizou-se pesquisa de natureza exploratória e descritiva, a partir de revisão bibliográfica e por meio de entrevistas estruturadas com perguntas fechadas. Após tabulação dos dados, realizou-se análise estatística descritiva. Verificou-se que há pouca utilização de ferramentas de gestão nas propriedades familiares do município de Pinheiro Preto. A maioria absoluta (91\%), faz o uso de simples anotações em cadernetas, geralmente incompletas e pouco abrangentes e a grande maioria, (76\%) toma as decisões "em conversa com familiares" sem utilizar dados de safras anteriores. A pesquisa aponta para a necessidade de estender esforços visando deixar claro aos produtores a importância do uso das ferramentas de gestão em suas propriedades.
\end{abstract}

PALAVRAS-CHAVE: Agricultura familiar. Ferramentas de Gestão. Pinheiro Preto.

\section{THE USE OF MANAGEMENT TOOLS IN THE FAMILY PROPERTY OF PINHEIRO PRETO - SC}

\section{ABSTRACT}

Family farming is a form of production, responsible for generating income for many Brazilian families. Rural property, even if familiar, needs to be seen as a business, where farmers are to be regarded as profit-driven entrepreneurs, control costs, plan and manage their activities. The objective of this research was to identify how the management occurs, what are the main management tools used by the producers 
and what are the main factors influencing the adoption of these tools in the family properties of Pinheiro Preto-SC. To achieve this goal, research was exploratory and descriptive, based on a bibliographical review and structured interviews with closed questions. After data tabulation, a descriptive statistical analysis was performed. It was verified that there is little use of management tools in the family properties of the municipality of Pinheiro Preto. The absolute majority (91\%) use simple annotated notes, usually incomplete and not very comprehensive, and the vast majority $(76 \%)$ make the decisions "in conversation with family members" without using previous harvest data. The research points to the need to extend efforts to make clear to producers the importance of the use of management tools in their properties.

KEYWORDS: Family agriculture. Management Tools. Pinheiro Preto.

\section{INTRODUÇÃO}

A agricultura familiar é uma forma de produção e organização que com o passar do tempo vem se modificando. É uma atividade reconhecida como promotora do desenvolvimento local com sustentabilidade econômica, social e ambiental. Esta pode contribuir com a manutenção das famílias no meio rural, produção de alimentos, erradicação da pobreza, geração de empregos e conservação dos recursos naturais e da biodiversidade, preservação da cultura, tradições e diversidade multiétnica (FAO, 2014). Mas, a importância da agricultura familiar vai além. É dentro da propriedade que a própria família faz o controle dos recursos utilizados na produção, recursos estes que são: terra, animais, culturas, material genético, casas, galpões, máquinas, conhecimento (Know-how) e planeja como combinar cada um deles (PLOEG, 2013).

No Brasil, os agricultores familiares ${ }^{1}$ respondem por $84,4 \%$ dos estabelecimentos do país, ocupam $24,3 \%$ da área cultivada e empregam $74,4 \%$ da mão de obra do setor agropecuário. A agricultura familiar também é predominante no estado de Santa Catarina, ou seja, 87,3\% (168.544) dos estabelecimentos são familiares. O município de Pinheiro Preto, recorte para o estudo, possui 185 propriedades enquadradas como de agricultura familiar, correspondendo a 89,37\% do total de estabelecimentos (IBGE, 2006). Observa-se neste sentido que trata-se de um município, onde a agricultura familiar é representativa.

Sendo assim, para que a agricultura familiar sobreviva e seja fortalecida, é preciso, incessantemente buscar estratégias eficientes, tanto de produção, quanto na comercialização e, especialmente aquelas relacionadas à gestão. Mecanismos gerenciais são importantes para dar suporte às atividades da propriedade familiar, visando manter a sustentabilidade e a competitividade (CLEMENTE et al., 2010).

Em especial, as pequenas propriedades rurais familiares apresentam uma maior precariedade no que tange aos métodos utilizados para a projeção e a aferição dos resultados, em relação à disponibilidade de informação. Além disso, as propriedades que são cultivadas com mão de obra basicamente familiar, normalmente possuem baixo grau de organização e planejamento, e raramente utilizam práticas de registros das informações relevantes para embasar o processo decisório (CLEMENTE et al., 2010).

As organizações rurais e familiares ou de qualquer outro tipo, tendem a se tornar mais competitivas à medida que congregam tecnologia e gestão na produção

\footnotetext{
${ }^{1}$ Neste estudo, considera-se estabelecimento de agricultura familiar os que contemplarem o que prevê a Lei Federal 11.326 de 24 de julho de 2006 (BRASIL, 2006).
} 
e comercialização de produtos. Impulsionadas pelas alterações no ambiente socioeconômico e institucional, as cadeias produtivas agroindustriais têm sofrido significativas transformações, pressionando também os empreendimentos rurais familiares a assumirem características empresariais. Sendo assim, torna-se essencial a necessidade de adoção de ferramentas de gestão para acompanhar a evolução do mercado, bem como, o primeiro passo para alcançar a eficiência técnica e de gestão (MACHADO \& NANTES, 2011).

No entanto, apesar da perceptível importância do uso de ferramentas de gestão nas propriedades rurais, "deve se reconhecer que pouco tem sido feito em termos de desenvolvimento de técnicas de gestão que contemplem as particularidades da agricultura familiar e as formas pelas quais ela pode se inserir de forma competitiva e sustentada no mercado" (DEPONTI, 2014).

Nesta mesma perspectiva CREPALDI (2012) assevera que todas as atividades que são desenvolvidas no meio rural, independente de tamanho, obrigatoriamente, necessitam de controles eficientes, sendo essencial o registro dos dados importantes, não basta apenas, os agricultores guardarem na memória as informações, as quais com o tempo poderão ser esquecidas, sendo que estas informações podem ser primordiais no momento da comercialização ou da apuração dos resultados.

O impacto do uso de práticas de gestão nas propriedades familiares, pode ser observado tanto em aspectos econômicos como sociais e ambientais. Segundo BREITENBACH (2014), quando se trata do aspecto econômico, talvez seja a forma que a gestão rural mais contribua e que seja percebida, já que é a partir das práticas de gestão que o agricultor tem conhecimento se as atividades que ele vem desempenhando, estão sendo economicamente viáveis ou não. Nos casos negativos, o agricultor, por meio da gestão, poderá estabelecer estratégias para a identificação ou eliminação dos gargalos que estão impedindo a eficiência econômica.

No aspecto social é mais difícil a mensuração da importância da gestão, no entanto, as práticas permitem administrar o tempo, a divisão de tarefas, a escolha de atividades e fatores que interferem no bem-estar dos agricultores. Por fim, nas questões ambientais, uma forma prática de visualizar essa contribuição está relacionada ao Código Florestal Brasileiro, pois, embora exista há décadas, agora é que se pretende utilizá-lo de forma efetiva, como instrumentos regulatórios (concessão de crédito só para unidades produtivas regulares), ou punitivos, como as multas para os irregulares (BREITENBACH, 2014).

Conforme observado no desenvolver das reflexões, a gestão rural tem um papel de considerável importância para a agricultura, mas tem recebido pouca atenção por parte dos agricultores e dos profissionais que prestam assistência técnica e extensão rural, especialmente quando o foco é a gestão de custos. 0 objetivo desta pesquisa foi identificar como ocorre a gestão, quais as principais ferramentas de gestão utilizadas pelos produtores e os principais fatores que influenciam na adoção dessas ferramentas, nas propriedades familiares de Pinheiro Preto - SC.

\section{MATERIAL E MÉTODOS}


Essa seção apresenta os aspectos metodológicos que nortearam a realização desta pesquisa. Trata-se de uma pesquisa de caráter exploratório e descritivo. A pesquisa exploratória visa prover, ao pesquisador, subsídios de conhecimento sobre o tema em estudo (MATTAR, 2012). A pesquisa descritiva é utilizada quando o propósito for descrever características de grupos, estimar a proporção de indivíduos que tenham determinadas características ou comportamentos e descobrir se há relação entre as variáveis (MATTAR,2012), ou seja, aprofundar a descrição de uma determinada realidade (TRIVINOS, 2015). Neste sentido, são apropriadas para que se conheça o perfil dos agricultores de Pinheiro Preto, se eles fazem uso de ferramentas de gestão em suas propriedades e quais fatores influenciam para este comportamento. Apresenta-se também, nesta seção, delimitação geográfica e o público alvo, em seguida o método utilizado para a coleta e análise dos dados e por fim as variáveis investigadas.

\section{Delimitação do público alvo}

A presente pesquisa foi desenvolvida junto aos agricultores familiares do município de Pinheiro Preto - SC. A escolha se deu em razão dos pesquisadores desenvolverem suas atividades profissionais neste município, e então os resultados contribuiriam para o desenvolvimento de atividades de extensão no mesmo.

Pinheiro Preto se localiza no meio oeste de Santa Catarina, no Vale do Rio do Peixe. De acordo com dados da FECAM (2015), o município está localizado a 696 metros do nível do mar, abrangendo uma área de $65,71 \mathrm{Km}^{2}$, IDH de 0,77 . A população fica em torno de 3.502 habitantes, e destes, 45,98 \% moram na zona rural. Suas principais atividades agrícolas são uva, pêssego e maçã (lavouras permanentes), e milho, soja e trigo (temporárias). O rebanho do município está concentrado em aves, suínos e bovinos, contando ainda com produção de leite e ovos (IBGE, 2015).

Para a definição do cálculo amostral, empregou-se a fórmula de tamanho mínimo definida por BARBETTA (2002). O nível de confiabilidade utilizado foi de $86 \%$.

$\mathrm{n}=\mathrm{N} \cdot \mathrm{n}_{0} / \mathrm{N}+\mathrm{n}_{0}$

$\mathrm{n}_{0}=1 / \mathrm{E}^{2}$

Onde:

$\mathrm{n}$ : tamanho da amostra;

N: tamanho da população;

$\mathrm{n}_{\mathrm{o}}$ : uma primeira aproximação para o tamanho amostra;

E: erro amostral tolerável;

$$
\begin{aligned}
& \mathrm{n}_{\mathrm{o}}=1 / \mathrm{E}^{2} \\
& \mathrm{n}_{\mathrm{o}}=1 / 0,14^{2} \\
& \mathrm{n}_{\mathrm{o}}=1 / 0,0196 \\
& \mathrm{n}_{\mathrm{o}}=51,02
\end{aligned}
$$

Calculou-se o tamanho da amostra utilizando a seguinte equação. 


$$
\begin{aligned}
& n=N \cdot n_{\circ} / N+n_{\circ} n \\
& n=185 \times 51,02 / 185+51,02 \\
& n=9.438,7 / 236,02 \\
& n=39,99 \\
& n=40
\end{aligned}
$$

A escolha dos entrevistados foi por conveniência, realizada de acordo com os recursos financeiros e tempo disponível dos pesquisadores. Foram entrevistados 42 agricultores familiares. Ainda que a amostra não tenha representatividade estatística, em larga medida ela tende a representar a realidade da região estudada.

\section{Procedimento de Coleta dos dados}

Os instrumentos utilizados, na pesquisa exploratória, para coleta de dados foram levantamentos bibliográficos, uma das formas mais rápidas e econômicas de aprofundar sobre o tema (MATTAR, 2012). As fontes utilizadas foram livros, artigos científicos e dados disponibilizados por órgãos governamentais.

Já na pesquisa descritiva utilizou-se como método de coleta de dados a aplicação de questionário com perguntas fechadas, realizados por um entrevistador pessoalmente. O questionário é uma técnica de investigação composta por um conjunto de questões a fim de obter informações sobre conhecimentos, crenças, interesses, sentimentos e comportamento presente ou passado dentre outras (GIL, 2011).

O questionário era composto de duas seções. A primeira se referindo às características socioeconômicas dos agricultores, como: a) idade; b) gênero; c) nível de instrução; d) número de residentes no domicílio; e) anos de atividade na propriedade; f) área total da propriedade; e g) principais atividades desenvolvidas na propriedade.

A segunda seção contemplou questões sobre os aspectos referentes às práticas de gestão realizadas na propriedade, como: a) tem ou faz uso de algum tipo de ferramenta de gestão e qual ferramenta utiliza, e se não o faz, por quê? b) faz algum tipo de planejamento em sua propriedade? O que produzir? Atividades mais adequadas? Atividades mais lucrativas? Combinação ideal entre as atividades; c) realiza o controle separado por atividade ou todos juntos; d) qual suporte utiliza para a tomada de decisão no momento da comercialização? e) de que forma toma as decisões em sua propriedade? f) tem interesse em adquirir mais conhecimento sobre gestão? g) participa de palestras, cursos e treinamentos oferecidos, sobre gestão das propriedades? h) qual melhor forma, você considera, que facilitaria o gerenciamento de sua propriedade? e, por fim i) recebe assistência técnica, pelos órgãos públicos, sobre gestão?

Os dados foram coletados por meio de um questionário, os quais foram aplicados junto à Agropecuária Pazini (a única que havia no município), em clientes que ali compareciam. A coleta ocorreu no município de Pinheiro Preto, durante os 
meses de janeiro, fevereiro e março de 2015, o tempo utilizado para cada questionário foi em média 30 minutos.

\section{Método de análise}

Os dados após coletados foram digitados, tabulados e analisados por meio do software GNUPSPP, que é um software livre (General Public License - Free Software Foundation), o qual é muito semelhante ao SPSS, programa de propriedade da IBM. Inicialmente se fez uma análise dos dados utilizando o método de estatística descritiva, posteriormente, foram realizadas análises de regressão, com intuito de identificar algumas variáveis que influenciam os produtores na realização de gestão e planejamento dentro das propriedades.

Nesta etapa, se buscou identificar se as variáveis socioeconômicas influenciam na condição do agricultor "Tem ou faz uso de alguma ferramenta de gestão em sua propriedade".

No segundo momento, selecionou-se algumas variáveis do questionário a fim de testar se estas influenciam ou não na condição de o agricultor ter conhecimentos sobre os custos e receitas de suas propriedades. A escolha destas variáveis se deu a partir da revisão da literatura.

QUADRO 1. Modelos e variáveis utilizadas nas análises.

\begin{tabular}{|c|c|c|}
\hline Modelo & Variável dependente & Variáveis independentes \\
\hline \multirow[t]{2}{*}{$\begin{array}{c}\text { Modelo } \\
1\end{array}$} & 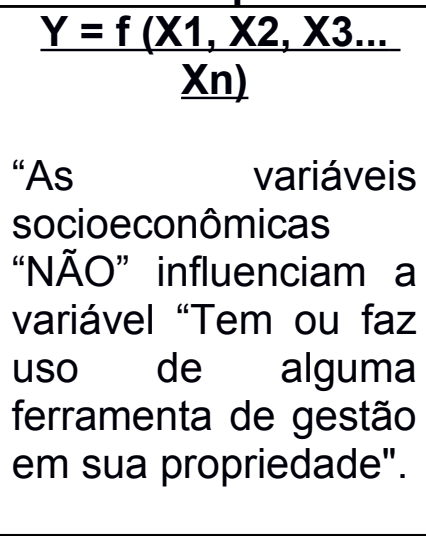 & $\begin{array}{l}\text { X1: sexo; } \\
\text { X2: idade; } \\
\text { X3: escolaridade; } \\
\text { X4: área da propriedade; X5: tem conhecimento } \\
\text { sobre os custos e receitas de sua produção; } \\
\text { X6: tem interesse em adquirir mais } \\
\text { conhecimento sobre gestão; } \\
\text { X7: participa de cursos sobre gestão; } \\
\text { X8: recebeu auxílio sobre gestão de assistência } \\
\text { técnica governamental; } \\
\text { X9: quantidade de anos que exerce atividade; }\end{array}$ \\
\hline & 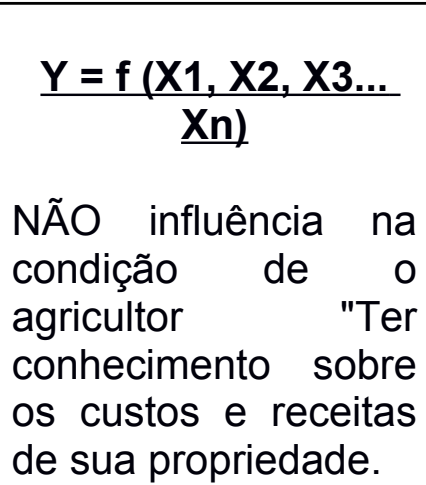 & $\begin{array}{l}\text { X1: sexo; } \\
\text { X2: idade; } \\
\text { X3: escolaridade; } \\
\text { X4: área total da propriedade; } \\
\text { X5: anos de atividade na propriedade; } \\
\text { X6: recebe orientação sobre gestão de } \\
\text { assistência técnica governamental; } \\
\text { X7: tem interesse em adquirir mais } \\
\text { conhecimento; } \\
\text { X8: participa de treinamentos e palestras; }\end{array}$ \\
\hline
\end{tabular}

No modelo de regressão, desta forma, assume-se como: $Y=f(X 1, X 2, X 3 \ldots$ $\mathrm{Xn}$ ), onde $\mathrm{Y}$ representa se na propriedade "Tem ou faz uso de alguma ferramenta de gestão em sua propriedade". Obteve-se como resultado da análise o $\mathrm{R}^{2}$, o qual demonstra o poder de explicação do modelo, ou seja, o quanto a variação conjunta ENCICLOPÉDIA BIOSFERA, Centro Científico Conhecer - Goiânia, v.14 n.25; p. 214 
de todas as variáveis independentes $(\mathrm{X})$ explicam as variações de $(\mathrm{Y})$. Também se obteve o resultado do "test $t$ " (o qual compara a variável dependente e sua relação com a independente), o valor de aceitação é um valor padronizado que determina como região de aceitação os valores entre -1,96 e +1,96, com nível de significância de até 0,05 . Pelo $F$ verifica-se o quanto a variação conjunta de todas as independentes $(\mathrm{x})$ explicam as variações de $(\mathrm{Y})$. O teste $\mathrm{F}$ é o mesmo da ANOVA, que para o caso de regressão múltipla, mede o grau de associação em que as variáveis independentes podem explicar as variações da variável dependente. A partir dos resultados pode-se inferir se as variáveis independentes ( $x$ ) não contribuem significativamente para a variação de (Y), ou seja, aceitando ou rejeitando a hipótese nula.

\section{RESULTADOS E DISCUSSÃO}

\section{Caracterização das propriedades de Pinheiro Preto - SC}

Com base nos dados coletados na pesquisa, em relação à área total das propriedades, observou-se que $42,85 \%$ das mesmas, contam com até 18 hectares, e $45,25 \%$ de 18 a 36 hectares. As propriedades de 37 a 54 hectares somam 7,14\% e as de 55 a 72 hectares, 4,76\%. Analisando as principais atividades produtivas praticadas, destaca-se que a maioria dos estabelecimentos não se detém em apenas uma, mas procura combinar várias delas. Os achados demonstraram que a produção de grãos e bovinocultura foram citados como presentes em $73,80 \%$ e $59,52 \%$ respectivamente. A diversificação das atividades em agricultura familiar é importante porque reduz os riscos e incertezas do negócio rural e pode gerar maior lucratividade ao produtor, permitindo a redução do impacto econômico oriundo de crises no setor e de vulnerabilidades referentes ao clima, mercado, pragas e doenças (ANDRADE et al., 2011).

$\mathrm{Na}$ figura 1, é possível observar quais são as principais atividades desenvolvidas nas propriedades familiares de Pinheiro Preto - SC. É necessário explicitar, que nesta questão era possível escolher mais de uma opção de resposta, portanto os dados apresentados mostram a quantidade de propriedades que conta com determinada atividade, por exemplo, das 42 propriedades, 31 delas contam com produção de grãos, 18 com fruticultura, e assim por diante. A principal justificativa, para a diversificação, citada pelos agricultores entrevistados, é de que com os custos altos existentes, uma só atividade não gera renda suficiente para manter a propriedade. 


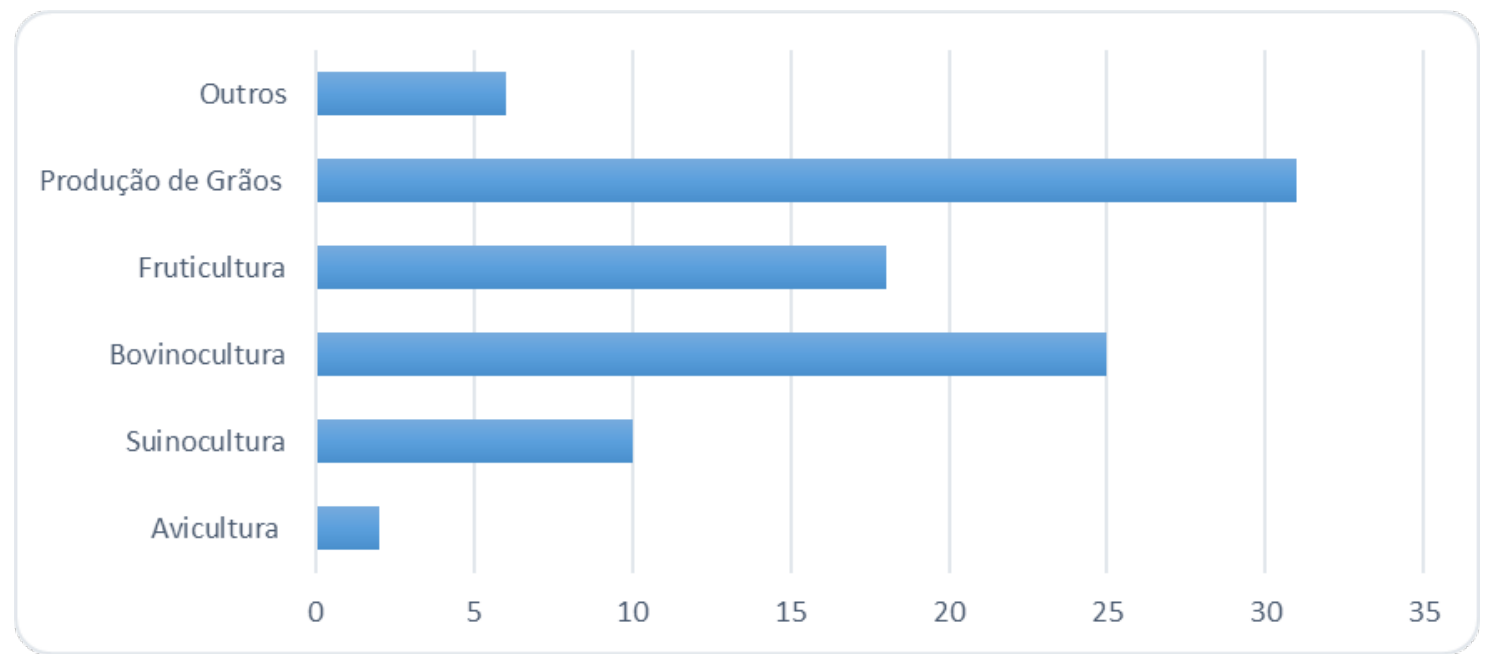

FIGURA 1 - Principais Atividades Agropecuárias nas Propriedades Familiares de Pinheiro Preto - SC.

Fonte: Dados da pesquisa.

Dos 42 entrevistados, $97,62 \%$ são do sexo masculino e apenas $2,38 \%$ do sexo feminino. Estes dados demonstram a predominância dos homens nas atividades de gestão das propriedades. O homem ainda é o chefe da família, e na maioria das vezes o responsável pela compra dos insumos e venda da produção. Os resultados obtidos neste estudo vão ao encontro com os apresentados por DAMETTO \& MORETTO (2011), em estudo desenvolvido no município de Tapejara - RS, no qual buscou-se identificar a estrutura e as principais características do processo produtivo e do fator trabalho das propriedades rurais ligadas ao setor primário, os achados revelaram que $92 \%$ dos responsáveis pela gestão da propriedade eram do sexo masculino, o que denota a predominância masculina em atividades de gestão no meio rural é significativa e recorrente.

Em relação à faixa etária dos entrevistados pode-se observar que a maioria encontra-se entre 50 e 59 anos, sendo que uma parte considerável possui mais de 60 anos (gráfico 2). Esses dados sinalizam a tendência do envelhecimento rural, preocupação esta que é compartilhada pelos autores CINTRA\& BAZOTTI (2012), os quais destacam o forte envelhecimento das populações rurais na região sul do Brasil, bem como pelo estudo de ZENARO et al. (2015) desenvolvido no vizinho município de lomerê - SC, em que os resultados demonstram que $48 \%$ dos gestores da propriedade têm idade superior a 53 anos. 


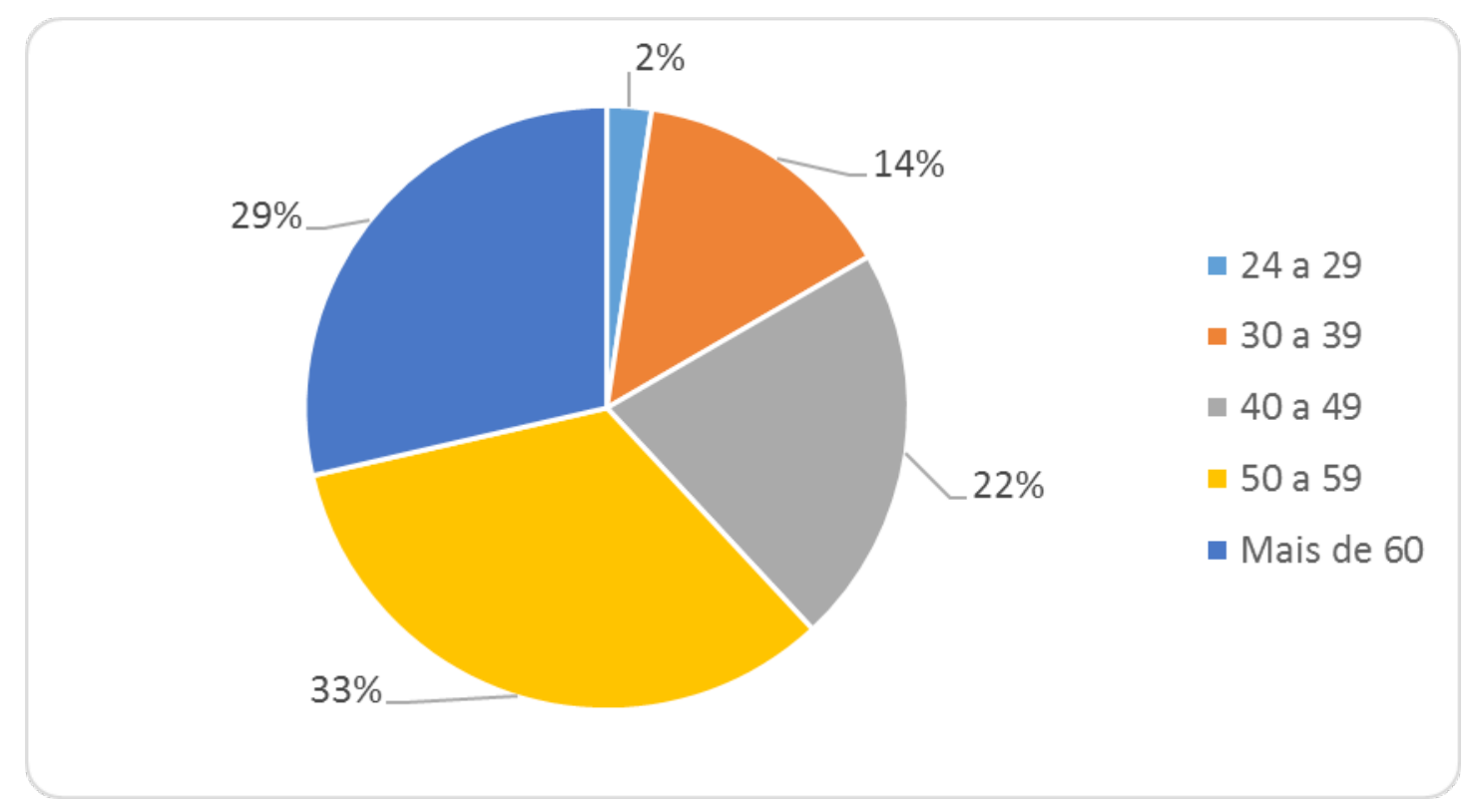

FIGURA 1 - Faixa etária da amostra entrevistada.

Fonte: Dados da pesquisa

A média de anos de atividade nas propriedades pesquisadas condiz com o intervalo de faixa etária observado. Em Pinheiro Preto, os agricultores familiares estão em média há 37 anos na sua propriedade. Resultados que se assemelham aos identificados por COSTA et al. (2014), os quais informaram que $30 \%$ dos pesquisados estão na propriedade a mais de 25 anos.

A composição da força de trabalho familiar nas propriedades entrevistadas em Pinheiro Preto - SC é, em média, de 3,92 pessoas. Situação similar também foi constatada por COSTA et al. (2014). Em geral, está na propriedade, o pai, a mãe e um dos filhos, sendo que os filhos menores de idade também auxiliam em diversas atividades, não raro em visitas às propriedades observa-se os filhos desenvolvendo atividades de menor intensidade, como auxiliar os pais na lavagem da infraestrutura de ordenha, no manejo do gado etc. No entanto, muitos filhos já migraram para a cidade em busca de trabalho e/ou estudo, muitas vezes deixando a propriedade aos cuidados exclusivos dos pais, já acima dos cinquenta anos. Ainda há situações onde o filho apenas volta para casa para dormir, estudando e trabalhando na cidade.

Em relação ao grau de escolaridade dos entrevistados observa-se que apenas $2 \%$ possui ensino superior e $36 \%$ ensino médio, como pode ser melhor analisado por meio da figura 3 . Resultado este que retrata como os agricultores ainda possuem um nível de escolaridade deficitário. Esse aspecto, pode, de certa forma, interferir na utilização de tecnologias para facilitar a gestão rural. De acordo com DEPONTI (2014), muitas vezes os jovens agricultores deixam seus estudos para auxiliar em suas propriedades, e estes são os prováveis sucessores a dar continuidade e gerir a propriedade, o que dificulta o acesso e uso de novas tecnologias. 


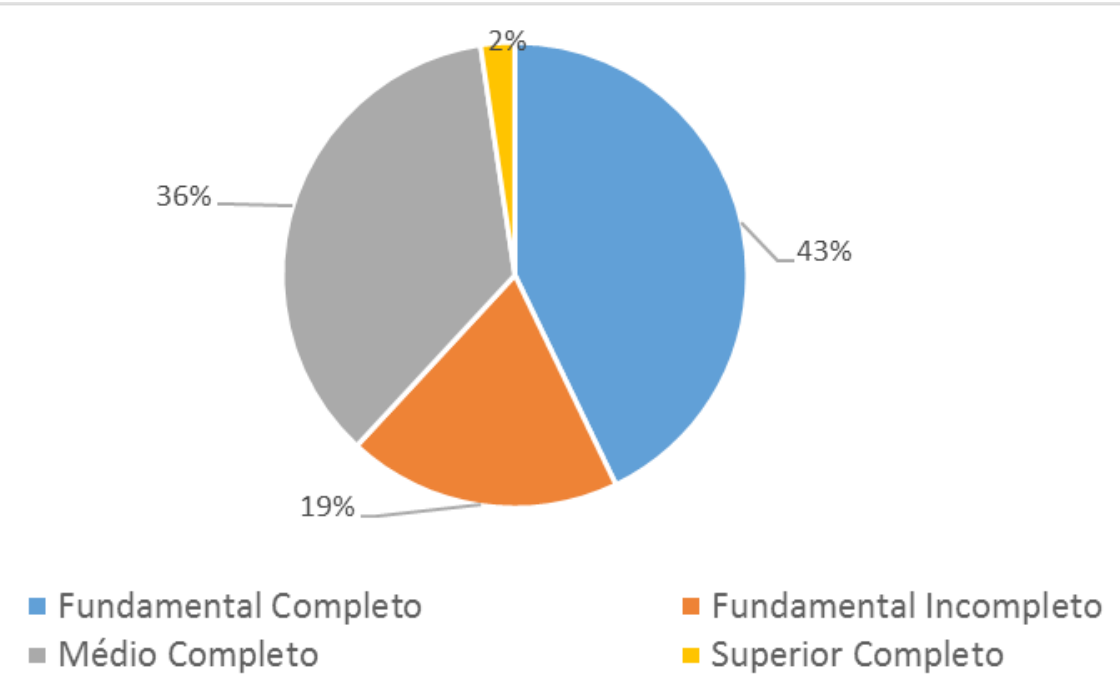

FIGURA 2 - Grau de Escolaridade dos Agricultores Familiares Entrevistados Fonte: Dados da pesquisa

\section{Aspectos referente às práticas de gestão realizadas nas propriedades}

Nesta seção serão apresentados os aspectos referentes às práticas de gestão que são realizadas pelos agricultores familiares em Pinheiro Preto - SC. Resultados, sobre o uso de ferramentas de gestão, se faz planejamento de sua produção, se tem conhecimentos sobre os custos de produção, se realiza o controle da propriedade de forma geral ou por atividade, como realiza o processo de tomada de decisão sobre comercialização e de forma geral, se tem interesse em adquirir mais conhecimento sobre gestão e qual método ou melhor se aplica ou facilita o gerenciamento da propriedade.

Investigando se os produtores rurais de Pinheiro Preto, realizavam algum tipo de prática de gestão, em suas propriedades, as respostas revelaram que $66,66 \%$ fazem de forma parcial, $23,82 \%$ disseram que não e $9,52 \%$ responderam que sim. Observa-se neste sentido, que apesar de atividades de gestão serem importantes para o desenvolvimento das propriedades, poucas ainda aderiram de forma integral. Para BATALHA et al., (2004), alguns fatores não privilegiam os aspectos de gestão nas propriedades rurais, tais como a pouca cultura (formal e informal) do agricultor neste assunto, o baixo nível de qualificação dos técnicos extensionistas em tecnologias de gestão, a inadequação das ferramentas disponíveis na literatura, a descapitalização dos agricultores (que impede a contratação de técnicos efetivamente qualificados no assunto) e as políticas públicas de estímulo ao setor. Aliada às dificuldades anteriormente mencionadas, destaca-se a falta de compreensão da real necessidade de realizar tais registros e a dificuldade de realizar os registros de controle de custos, de despesa e de receita.

Dos agricultores que de alguma forma realizam algum tipo de registro das informações referente aos processos produtivos e de comercialização, $91 \%$ dos respondentes disseram utilizar anotações simples em caderneta ou caderno e apenas $9 \%$ utiliza-se de planilhas simples no computador e nenhum dos respondentes faz uso de softwares específicos. Dentre os respondentes que não utilizam nenhuma prática de gestão, $50 \%$ alega que fazer a gestão da propriedade é 
muito complicado, $40 \%$ não faz, alegando não ter conhecimento e $10 \%$ acredita que não é importante, conforme pode se observar na figura 4.

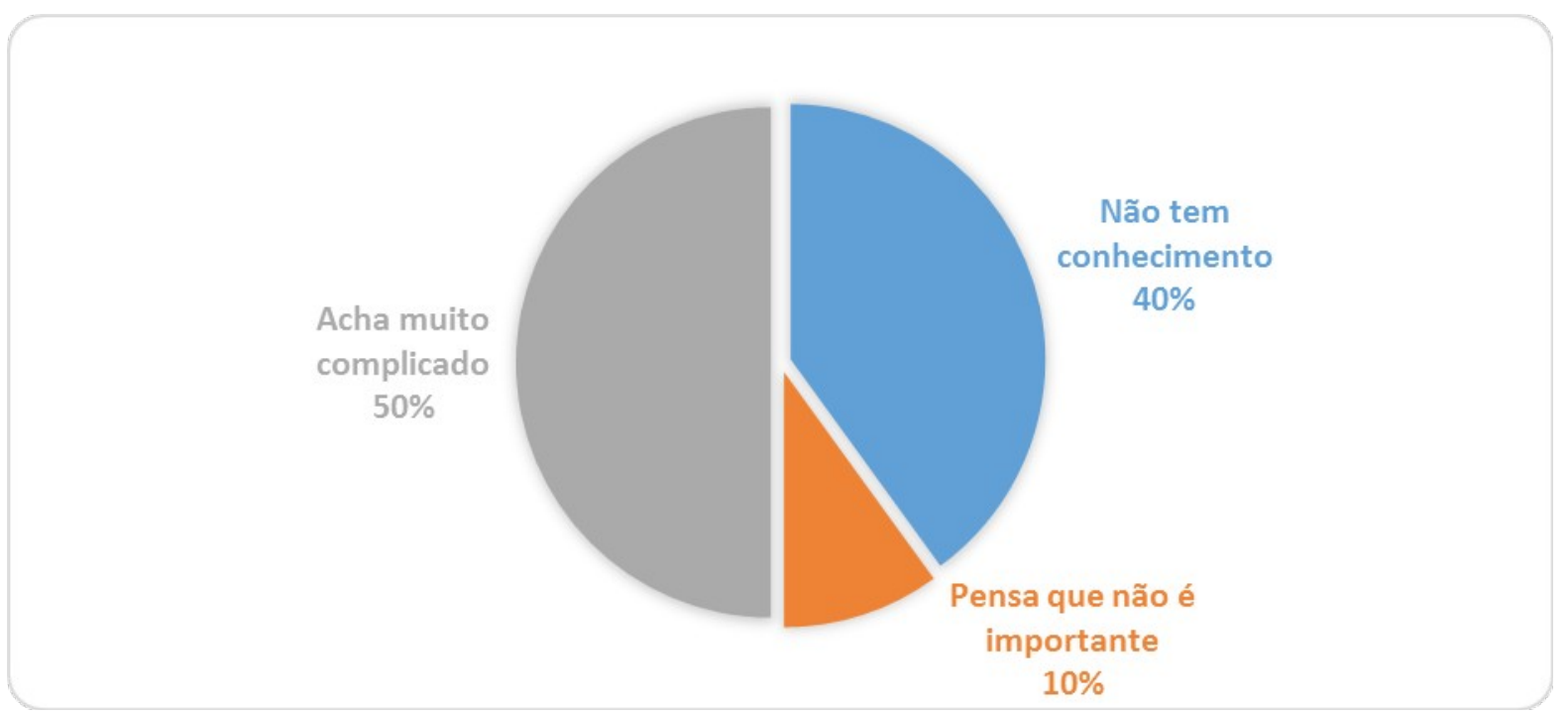

FIGURA 4 - Porque os agricultores familiares não fazem gestão da sua propriedade. Fonte: Dados da pesquisa.

$\mathrm{Na}$ pergunta seguinte foram indagados se conheciam a respeito dos custos e receitas da propriedade: $88,10 \%$ disseram que conheciam "parcialmente", e apenas $11,90 \%$ respondeu que conheciam totalmente. Comportamento semelhante foi observado nos Agricultores do Vale do Cai - RS, onde os mesmos faziam parte de um projeto piloto sobre a possibilidade de introduzir tecnologias de informação e de comunicação para a agricultura familiar. Os agricultores apresentaram-se receosos, preocupados e desconfiados. Primeiro porque é uma prática diária e eles não têm costume de fazer anotações (registros). Em um segundo lugar, porque ainda não compreenderam de fato, como este costume poderá auxiliá-los no futuro da gestão e na tomada de decisão, mesmo sendo explicado e orientando eles ainda não assimilaram a importância. Assim, "a gestão do estabelecimento rural pela agricultura familiar caracteriza-se por algo que se denominou "agrura", ou seja, uma dificuldade, um empecilho, uma amargura, uma aflição" (DEPONTI, 2014).

Outro fator que complica o controle de gestão é a questão de as propriedades terem atividades diversificadas. Dos entrevistados, 65\% respondeu que "controla" todas as atividades juntas, $10 \%$ faz o controle apenas da principal (de uma) atividade e $25 \%$ faz um controle individualizado, ou seja, cada atividade em separado. Para BREITENBACH (2014), "esse contexto imprime uma complexidade ao gestor, que precisa considerar todas as atividades como importantes e passíveis de análise financeira, bem como necessita gerir eficientemente as conexões entre essas atividades".

Quando perguntados sobre quais ferramentas utiliza para apoio no momento da decisão, apenas $2,4 \%$ respondeu que faz isso com o auxílio de anotações, controles e históricos da safra atual e anteriores. A maioria absoluta, $76,2 \%$, respondeu que decide em conversa com os familiares, o que significa que os dados, quando existentes, não pesam nas decisões. Ainda 19\% informaram que tomam decisões utilizando resultados obtidos em safras anteriores, mas sem controle específico e 2,4\% relataram que usam apenas a intuição. Essa realidade traz 
preocupações expressivas, cada dia que passa o setor agropecuário está em constante transformação e mais competitivo, situação que exige que o agricultor exerça uma gestão mais profissionalizada dentro de sua propriedade. Segundo CREPALDI (2012), a gestão rural no Brasil ainda ocorre utilizando critérios tradicionais e com padrão de desempenho inaceitável, sendo essa condição visualizada em todos os níveis de propriedade, pequenas, médias e grandes.

$\mathrm{Na}$ figura 5, é possível observar as respostas de frequência com que os agricultores realizam planejamento da produção, abrangendo respostas em relação ao o que produzir, a quais atividades são mais adequadas, quais são mais lucrativas e também qual a frequência (sempre, nunca, as vezes) que é feito um planejamento em relação à combinação ideal de atividades.

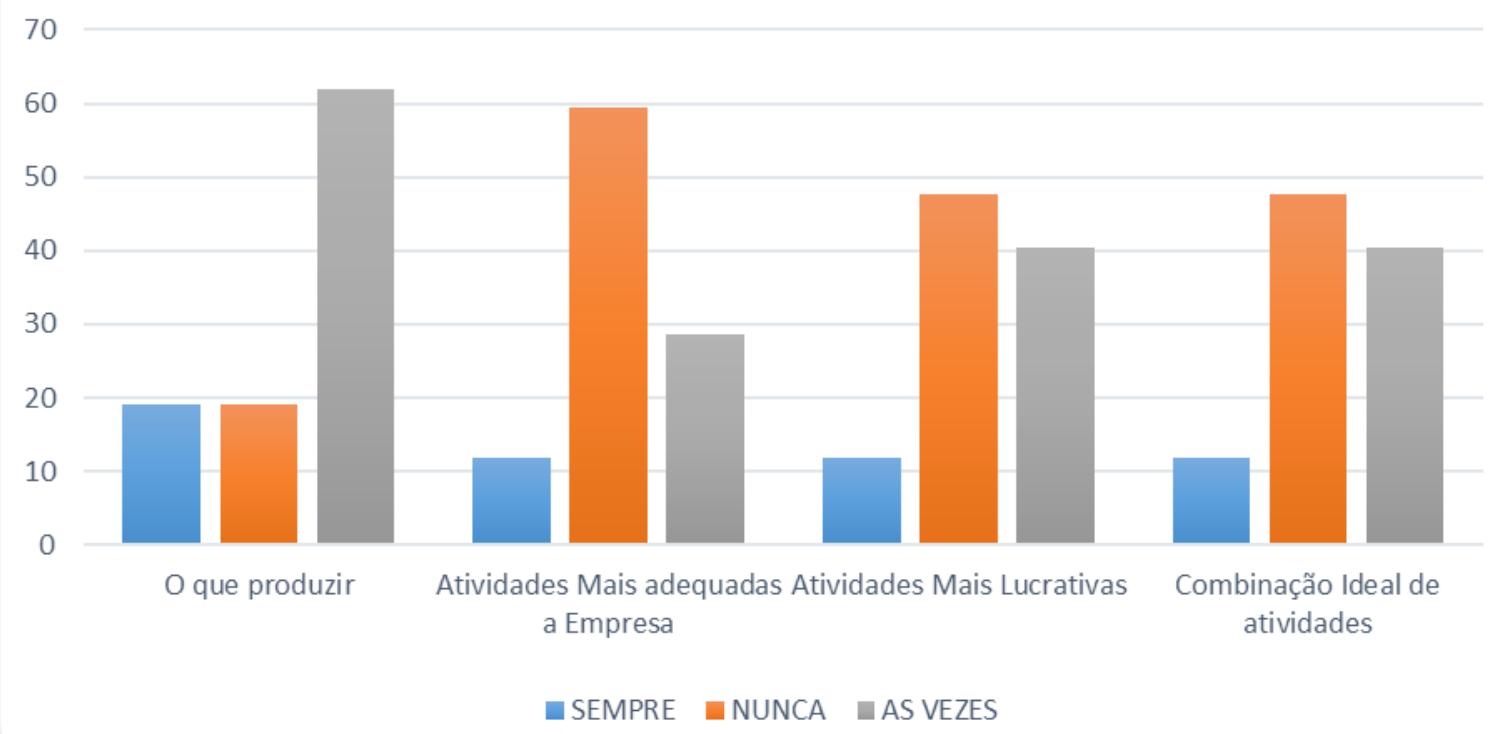

FIGURA 5 - Frequência com que o agricultor familiar realiza planejamento em relação à produção, adequação e lucratividade das atividades.

Fonte: Dados da pesquisa.

Em relação ao planejamento do que produzir, 61,9 \% disseram que o fazem às vezes, 19,05\% planejam sempre e 19,05 \% nunca planejam. Sobre quais atividades seriam as mais adequadas para a sua propriedade, 59,5\% revelou que nunca planeja, $28,6 \%$ às vezes e apenas $11,9 \%$ disseram que sempre planejam. Os agricultores também foram perguntados se planejam quais atividades são mais lucrativas: $11,9 \%$ dizem planejar sempre, $40,5 \%$, às vezes e $47,6 \%$ nunca. Planejamento sobre a combinação ideal de atividades, é feito sempre por $11,9 \%$, às vezes por $40,5 \%$ e nunca por $47,6 \%$. Observa-se com os dados apresentados, que os agricultores geralmente não realizam uma das etapas mais importantes da gestão, que é o planejamento. Por meio deste é que o agricultor teria condições de determinar os direcionamentos necessários para que a propriedade se desenvolvesse e se mantivesse no mercado. Nesta perspectiva KAY et al., (2014), salientam que os gestores precisam identificar as alternativas possíveis, analisar e escolher a alternativa que mais se aproxima de suas metas, devem estar sempre 
repensando suas decisões à medida que o contexto econômico, tecnológico e ambiental muda e que pode afetar a situação de oferta e demanda dos produtos.

Observa-se que existe pouco uso de gestão nas propriedades e quando há, é insatisfatória, produzindo pequenos resultados que influenciem na tomada de decisão. Então, os agricultores foram indagados qual seria o melhor método ou que facilitaria o gerenciamento de suas empresas? A maioria, $57,10 \%$ dos entrevistados, acredita que a utilização de planilhas prontas facilitaria o gerenciamento da propriedade, $14,30 \%$ apontaram os softwares computacionais simplificados e os que preferem anotações em caderneta somam $28,60 \%$.

Nesta perspectiva BREITENBACH (2014), pondera que a teoria utilizada para gerir os estabelecimentos rurais, os quais têm suas próprias características, é a mesma utilizada no gerenciamento de empresas urbanas. Pode não estar errado sob o ponto de vista contábil, no entanto, as ferramentas devem ser adequadas ao rural, caso contrário, há chance de se potencializar erros que comprometam o desempenho das propriedades. Sendo assim, é necessário desenvolver ferramentas e formas de apresentar aos agricultores, que sejam de fácil entendimento e utilização.

Este mesmo posicionamento é compartilhado por DEPONTI (2014), a qual destaca que a maioria dos softwares de controle de produção e de gestão rural disponíveis no mercado, estão totalmente desvinculados da possibilidade dos agricultores familiares utilizarem, de forma independente, pois são complexos e necessitam de apoio de experts. A alternativa apontada pela autora é a construção de ferramentas coletivas. Esse envolvimento dos agricultores pode desenvolver um sentimento de pertencimento do processo e assim obter um maior comprometimento por parte deles.

Além da produção outro fator importante dentro das operações agropecuárias é a comercialização de seus produtos. Sob este aspecto, $76,2 \%$ dos entrevistados revelou possuir comprador certo para sua produção e todos os anos negocia com o mesmo. Apenas 23,8\% analisa o mercado e busca o melhor preço de venda.

Quando questionados sobre seu interesse em adquirir mais conhecimento sobre gestão (figura 6), os resultados foram animadores, uma vez que $57 \%$ responderam que sim, $47 \%$ disseram que talvez e apenas $2 \%$ expressaram que não. 


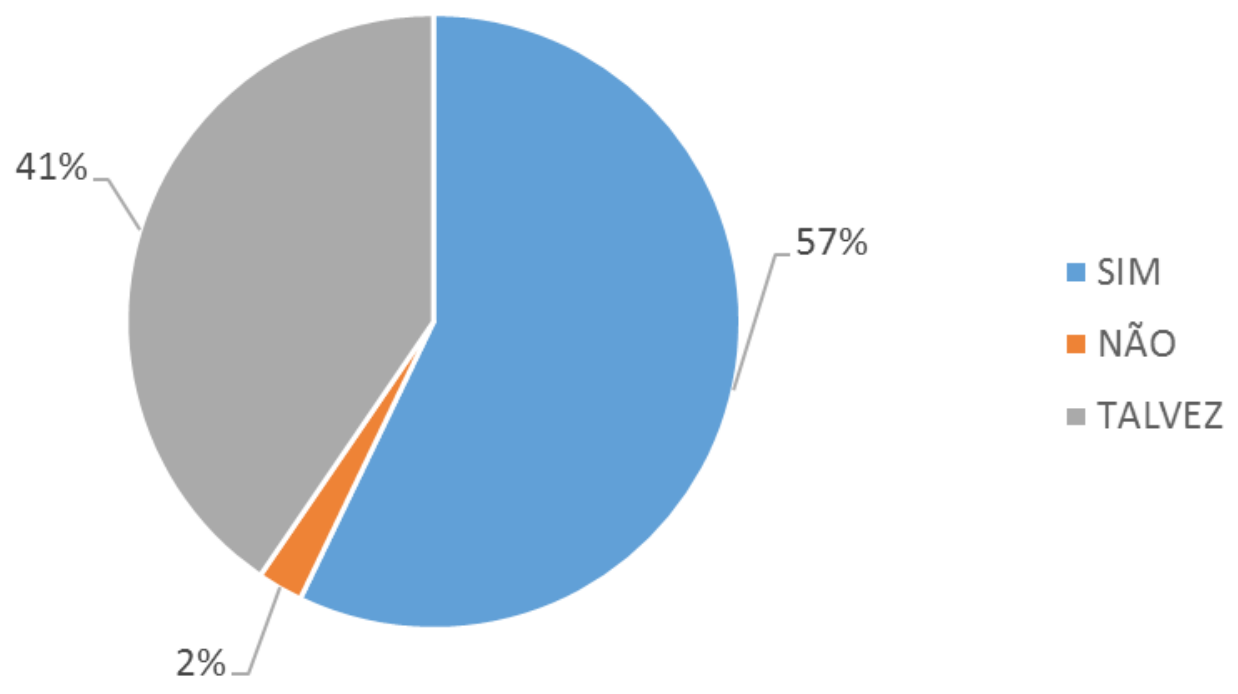

FIGURA 6 - Interesse dos agricultores familiares de Pinheiro Preto em adquirir mais conhecimento sobre gestão.

Fonte: Dados da pesquisa.

Assim como na pesquisa de MEDEIROS et al., (2012), observou-se que há interesse dos produtores em participar de cursos/treinamentos sobre gestão. Percebe-se que um dos motivos pela qual os mesmos enfrentam diversas dificuldades e obstáculos em controlar e apurar o resultado de suas produções é pela falta de conhecimento do assunto.

Porém, apesar dos produtores terem respondido na questão anterior que almejavam maior conhecimento sobre gestão, os achados demonstraram que quando há algum treinamento ou palestra sobre gestão, oferecidos pelas empresas de extensão ou representações comerciais, apenas $11,9 \%$ responderam que participam, $85,7 \%$ revela que "às vezes" e os que dizem que não somam $2,40 \%$.

Quanto a receberem algum tipo de informação sobre gestão pelos órgãos governamentais de assistência técnica, somente $14,30 \%$ responderam que sim/recebem, enquanto que $38,10 \%$ responderam que não recebem e $47,60 \%$ às vezes. Paralelamente apurou-se que muitas vezes esses produtores somente vão em busca dos órgãos governamentais para conseguir a papelada exigida pelas instituições financeiras, quando necessitam de recursos para custear a atividade.

No município de Pinheiro Preto, encontra-se um escritório da EPAGRI (Empresa de Pesquisa Agropecuária e Extensão Rural de Santa Catarina) para prestar assistência técnica aos produtores, entretanto muitos destes, não o procuram e em outras vezes não obtêm as informações desejadas. Somando-se a isso a extensão rural está na maioria das vezes focada nos aspectos produtivos e esquecendo da gestão.

$\mathrm{Na}$ última etapa do estudo, a fim de identificar os fatores socioeconômicos que influenciam os produtores a utilizarem ferramentas de gestão em suas propriedades, fez-se uma análise de regressão. Os resultados revelaram um $\mathrm{R}^{2}$ de 0,57 . Sendo assim, $57 \%$ das variações em $(X)$ explicam as variações em $(Y)$, ou seja, o quanto a variação conjunta de todas as variáveis independentes $(X)$ explicam as variações de $(Y)$. 
O resultado demonstrou também por meio do "test t" que todas as variáveis analisadas não influenciam para o produtor realizar algum tipo de gestão em sua propriedade. Analisando o conjunto total de variáveis o resultado foi um $F$ de 1,69 e "sig" 0,13 . A partir dos resultados pode-se inferir que as variáveis socioeconômicas, não influenciam em o produtor fazer uso de ferramentas de gestão em sua propriedade.

Também, se realizou uma análise de regressão a fim de identificar se o conjunto de fatores: sexo, idade, escolaridade, área total da propriedade, anos de atividade na propriedade, recebe orientação sobre gestão de assistência técnica governamental, tem interesse em adquirir mais conhecimento, participa de treinamentos e palestras, influencia na condição do agricultor "Ter conhecimento sobre os custos e receitas de sua propriedade".

Observou-se com os resultados que o poder de explicação das variáveis é de $\mathrm{R}^{2} 62 \%$. Também por meio do "test t" observou-se que a variável "anos de atividade" interfere nesta condição do agricultor com nível de significância sig 0,01. As demais variáveis, isoladamente, não influenciam significativamente.

Analisando o conjunto total de variáveis, o resultado foi um F de 2,60 e "sig" 0,03 . Pelo $F$ verifica-se o quanto a variação conjunta de todas as variáveis independentes $(x)$ explicam as variações de $(Y)$, sugerindo que o conjunto de variáveis analisadas influenciam na condição do produtor em "possuir conhecimento sobre os custos e receitas de sua propriedade", ou seja, todas as variáveis (sexo, idade, escolaridade, etc), influenciam o agricultor em "ter conhecimento sobre os custos e receitas da propriedade".

\section{CONCLUSÃO}

A agricultura familiar é relevante no agronegócio brasileiro e ainda assim, a aplicação de ferramentas de gestão no setor apresenta-se como um tema complexo, pouco trabalhado e documentado. De modo geral, não há aplicação de ferramentas eficazes de gestão nas propriedades de agricultura familiar de Pinheiro Preto- SC. Quando raramente existe o uso de alguma ferramenta, esta não produz os efeitos desejados, já que não gera informações úteis ao gerenciamento, capazes de auxiliar aos processos de tomada de decisão.

As análises de regressão revelaram que 0 conjunto de fatores socioeconômicos analisados não influenciam os agricultores em fazer uso de alguma ferramenta de gestão. No entanto, o fator "anos de atividade" influencia os agricultores quanto ao conhecimento sobre os custos e receitas de sua propriedade.

A pesquisa aqui apresentada não pretendeu ser conclusiva por si só, sendo subsidiária de trabalhos futuros que aspirem analisar, se a utilização de ferramentas de gestão nas atividades desenvolvidas pelos agricultores familiares permite a estes, melhorar suas condições de vida e os estimulam a permanecer no meio rural.

\section{REFERÊNCIAS}

ANDRADE, A. L. S.; GONTIJO, C. M.; FRANÇA, P. B. Gestão do agronegócio familiar: estudo de Caso da Fazenda Paraíso. Revista Brasileira de Gestão e Engenharia, n.3, p. 1-19, 2011. Disponível em <http://www.periodicos.cesg.edu.br/index.php/gestaoeengenharia>. Acesso em: 25 mai. 2015. 
BARBETTA, P.A.; Estatística aplicada às ciências sociais. 7. ed. Florianópolis: UFSC, 2011.

BATALHA, M.O.; BUAINAIN, A.M.; SOUZA FILHO, H.M.; Tecnologia de gestão e agricultura familiar. Gestão integrada da agricultura familiar. São Paulo: EDUFSCAR, p. 43-65., 2004.

BRASIL. Lei n. 11.326 de 24 de julho de 2006. Disponível em: < https://www.planalto.gov.br/ccivil_03/_Ato2004-2006/2006/Lei/L11326.htm>. Acesso em: 19/11/2016.

BREITENBACH, R. Gestão rural no contexto do agronegócio: desafios e limitações. Desafio Online, v.1, n. 2, 2014. Disponível em: < http://www.desafioonline.com.br/publicações>.

CINTRA, A. P. U.; BAZOTTI, A. População rural, agricultura familiar e transmissão do saber na região sul. Caderno IPARDES. v.2, n.1, p. 80-94, 2012. Disponível em: < file:///C:/Users/Usu\%C3\%A1rio/Downloads/485-1887-1-PB.pdf>. Acesso em: fev.2017.

COSTA, Z. F.; JOCOSKI, L. V. B.; HERSEN, A; STEFANO, S. R; RAMOS, R. P. Características socioeconômicas da agricultura familiar produtora de milho: um estudo de caso dos produtores Pinhão-PR. Ambiência (UNICENTRO), v. 10, p. 807828, $2014 . \quad$ Disponível em <http://revistas.unicentro.br/index.php/ambiencia/article/view/2393>. Acesso em: 25 mai. 2015.

CLEMENTE, A.; SOUZA, A.; TAFFAREL, M.; GERIGK, W. Perfil das propriedades rurais familiares e controle de custos na Região Centro-Sul do Paraná. Custos e @gronegócio on line, v. 6, n. 3, p. 21-43, 2010. Disponível em: http://www.custoseagronegocioonline.com.br/numero3v6/Perfil\%20e\%20controle $\% 20$ de $\% 20$ custos.pdf.

CREPALDI, S. A. Contabilidade rural: uma abordagem decisorial. $7^{a}$ ed. São Paulo, Atlas: 2012.

DAMETTO, A.; MORETTO, C. F. Agricultura familiar, processo produtivo e trabalho: uma pesquisa em propriedades rurais do município de TAPEJARA (RS). In: $6^{\circ}$ Encontro de Economia Gaúcha, RS, 2011. Disponível em <http://www.pucrs.br/eventos/eeg/?p=trabalhos>. Acesso em: 25 mai. 2015.

DEPONTI, C. M. As "agruras" da gestão da propriedade rural pela agricultura familiar. Revista Desenvolvimento Regional, Santa Cruz do Sul, v. 19, ed. especial, $\quad$ p. $\quad 9-24, \quad 2014 . \quad$ Disponível <https://online.unisc.br/seer/index.php/redes/article/view/5150>. Acesso em: 25 mai. 2015.

FAO - FOOD AND AGRICULTURE ORGANIZATION OF THE UNITED NATIONS. Towards stronger family farms: voices in the International Year of family ENCICLOPÉDIA BIOSFERA, Centro Científico Conhecer - Goiânia, v.14 n.25; p. 224 
farming, Roma, 2014. Disponível em: < http://www.fao.org/3/a-i4171e.pdf>. Acesso em: fev. 2017.

FECAM - Federação Catarinense de Municípios. Municipios. 2015. Disponível em: < "http://www.fecam.org.br/municipios".org.br/municipios>. Acesso em: 24 maio 2015.

GIL, C.A. Métodos e técnicas de pesquisa social. 6.ed. -4.reimpr. São Paulo: Atlas, 2011.

IBGE- Instituto Brasileiro de Geografia e Estatística. Produção da pecuária municipal 2015. Disponível em: < http://www.ibge.gov.br/home/estatistica/economia/ppm/2015/default_xls_perfil.shtm >. Acesso em: 08 nov. 2016.

IBGE- Instituto Brasileiro de Geografia e Estatística. Censo Agropecuário 2006. Disponível

http://www.ibge.gov.br/home/estatistica/economia/agropecuaria/censoagro/>. Acesso em: 20 maio 2015.

KAY, R. D.; EDWARDS, W. M.; DUFFY, P. A. Gestão de propriedades rurais, 7. ed. Porto Alegre: AMGH, 2014.

MACHADO, J. G. C. F.; NANTES, J. F. D. Adoção da tecnologia da informação em organizações rurais: o caso da pecuária de corte. Gestão \& Produção, v. 18, n. 3, p. 555-570, 2011. Disponível em: <http://www.scielo.br/pdf/gp/v18n3/09.pdf >. Acesso em: 16 jun. 2015.

MATTAR, N. F. Pesquisa de Marketing, edição compacta. 5. ed. Rio de Janeiro: Elsevier, 2012.

MEDEIROS, A. F. Q.; SOUZA, J. A.; OLIVEIRA, D. L.; PORTO, W. S. Controle e Apuração de Resultado na Agricultura Familiar sob a Ótica da Sustentabilidade de Produtores Rurais. Revista Eletrônica Saber Contábil, v. 2, n.1, p. 1-16, 2012.

PLOEG, J.D. Diez cualidades de la agricultura familiar. LEISA - Revista de Agroecologia, v. 29, $\mathrm{n}^{\circ} 4$, p. 6-8, 2013. Disponível em: < http://www.leisaal.org/web/images/stories/revistapdf/vol29n4.pdf >.

TRIVIÑOS, A. N. S. Introdução à pesquisa em ciências sociais: a pesquisa qualitativa em educação. 1.ed. - 23.reimpr. São Paulo: Atlas, 2015.

ZENARO, M.; MORAIS, C. B.; ALBERICI, C. Desenvolvimento rural na perspectiva da administração: estudo de caso em pequenas propriedades rurais do município de lomerê, SC. Unoesc \& Ciência - ACSA. v. 6, n. 2, p. 197-206, 2015. Disponível em: <file://C:/Users/Usu\%C3\%A1rio/Downloads/7862-31509-1-PB.pdf >. Acesso em: fev. 2017. 